\title{
As sequências
} textuais explicativas: relações entre texto e semântica cognitiva

JURACH, Jussara Maria. As sequências textuais explicativas: relações entre texto e semântica cognitiva. Entrepalavras, Fortaleza, v. 7, p. 215-231, jan./jun. 2017.

The expository textual sequence: interfaces between text and cognitive Semantics

Jussara Maria JURACH (Unioeste) jumariaju@yahoo.com.br
Resumo: Este artigo se propõe a identificar traços dos sistemas cognitivos de estruturação da linguagem em proposições constitutivas das sequências explicativas. Para tanto, estabelece associações entre os esquemas sequenciais explicativos, conforme definidos por Adam (2001; 2008), e as contribuições da Semântica Cognitiva, na perspectiva de Talmy (2001), pela identificação de sistemas cognitivos que atuam na estruturação conceitual da linguagem. Com esses fundamentos teóricos, foram realizadas análises de textos que têm como dominante a sequência explicativa, o que possibilitou identificar estruturas conceituais que sustentam as macroproposições constitutivas da explicação e, com isso, ampliar a compreensão sobre os recursos morfossintáticos presentes nos textos estudados, sem deixar de considerá-los também em seus aspectos discursivos.

Palavras-chave: Sequências explicativas. Cognição. Análise linguística. 
v. 7 (1)

215-231 jan/jun 2017

Abstract: This article aims at identifying traits from the cognitive systems of structuring language in constructive propositions of the explanatory sequences. To do so, it establishes associations between the explanatory sequential schemes, according to Adam (2001; 2008), and the contributions from Cognitive Semantics, in Talmy's perspective (2001), through the identification of cognitive systems that act on the conceptual structure of language. Based on this theoretical foundation, it analyzes texts in which the explanatory sequence is prevailing, which made possible the identification of conceptual structures that support the macro propositions of explanation and, thus, enlarge the understanding of morfossintatic resources present in the analyzed texts, while also considering them in their discursive aspects.

Keywords: Explanatory sequences. Cognition. Linguistic analysis.

\section{Introdução}

As sequências textuais são definidas por Adam (2001; 2008) como construtos esquemáticos desenvolvidos espontaneamente pela atividade cognitiva dos indivíduos a partir das experiências com os textos. É nessa abordagem que o autor remete à noção de protótipos e elabora esquematizações sobre as cinco sequências textuais de base: descritiva, narrativa, argumentativa, explicativa e dialogal. Dessa forma, o autor deixa claro o pressuposto cognitivo nas suas definições sobre as sequências textuais, apesar de não explorar este diretamente em suas análises. Tal observação nos leva a estabelecer relações entre essas definições e as contribuições da Semântica Cognitiva na perspectiva de Talmy (2001), o qual se dedica aos sistemas cognitivos de estruturação da linguagem, em uma abordagem conceitual.

Esse entrecruzamento teórico tem como foco identificar a atuação dos sistemas cognitivos de estruturação da linguagem nas sequências explicativas, a fim de buscar pontos de ancoragem para uma compreensão mais ampliada dos recursos morfossintáticos presentes nos esquemas sequenciais explicativos, situando esses recursos na relação textual-discursiva, sobretudo devido à perspectiva de Adam (2008), que situa as sequências no interior da sua Análise Textual do Discurso (ATD).

Com esse objetivo de associação teórica entre semântica cognitiva e as definições da sequência explicativa no interior da análise textual discursiva, analisamos dois textos com sequência explicativa dominante e verificamos a atuação de sistemas cognitivos de estruturação da linguagem, sobretudo referentes à relação entre parte e todo e causa e efeito, os quais auxiliam na compreensão de marcas linguísticas presentes nas macroproposições que constituem os textos explicativos. 


\section{Aproximações entre texto, discurso e Semântica Cognitiva}

Sobre a relação que estabelecemos entre texto, discurso e cognição, precisamos evidenciar três aspectos. O primeiro diz respeito ao fato de que a abordagem da semântica cognitiva talmyana não é estritamente formal e nem sobremaneira psicológica. O autor desenvolve um viés conceitual da estruturação da linguagem com foco nos sistemas perceptivos, a fim de verificar como os conceitos são experimentados pela mente.

Talmy (2001) destaca a atuação do sistema perceptivo visual na constituição das representações cognitivas e a interação desse sistema com aspectos ideacionais e afetivos. Considerando esses fatores, o autor parte de categorias conceituais básicas, como: tempo e espaço, força e causa, entidades e processos e movimento e localização, e considera que essas categorias configuram a estruturação linguística de categorias atribuídas a agentes cognitivos, como atenção, perspectiva, vontade e intenção e expectativa e afeto. Essas relações, conforme Talmy (2001, p. 3), guiam a estrutura semântica de formas lexicais e morfológicas, assim como os padrões sintáticos.

Nessa relação entre aspectos formais e psicológicos, a valorização da percepção visual e da experiência faz com que o autor não exclua de suas análises os aspectos culturais dos indivíduos. Isso fica explícito em suas considerações sobre o enquadramento cognitivo das narrativas, como demonstra Batoréo (2006), em estudo sobre narrativas em Língua Portuguesa produzidas por timorenses, falantes do Português como língua não-materna, considerando a abordagem talmyana de não valorizar apenas o conteúdo ideacional e experiencial, mas também o emotivo e perceptivo, fruto das relações entre perspectivas linguísticas, psicológicas e culturais. Tal aspecto voltado para a vivência cultural dos indivíduos faz com que a Semântica Cognitiva talmyana seja compatível com nosso interesse de estabelecer relações entre a abordagem conceitual e os pressupostos cognitivos presentes nas definições de Adam (2001; 2008) sobre as sequências textuais. Assim, neste artigo percebemos os traços da constituição textual e discursiva como resultantes da atividade cognitiva que atua na organização da linguagem.

O segundo aspecto a ser destacado nessas aproximações teóricas refere-se às relações estabelecidas por Adam (2008) entre texto e discurso. Ao elaborar a ATD, o autor situa a análise textual no interior

\footnotetext{
${ }^{1}$ Sobre as relações entre a análise textual do discurso e a análise do discurso de
} 
v. 7 (1)

215-231

jan/jun

2017

de uma conjuntura mais ampla, a da análise do discurso, mas explicita que seu foco de estudo é o nível textual, que tem como objeto as relações entre os níveis hierárquicos constitutivos dos textos. Esses níveis compreendem desde a planificação (o plano de elaboração do texto), as sequências textuais, as macroproposições (conjuntos de proposições que atendem aos contornos esquemáticos do texto) e as proposições (enunciados mínimos), até as unidades menores, as palavras. O fato é que na ATD tais níveis são considerados sem deixar de situá-los no plano das interações sociais, o que remete às formações sociodiscursivas, ao interdiscurso, aos atos de discurso e aos gêneros discursivos.

Sobre esse plano do discurso, ressaltamos aqui que o autor da ATD considera que os enunciados dos textos estão inseridos em um complexo social e histórico de práticas discursivas. Nessa linha de interesse, Adam parte da noção de formação discursiva como:

(...) uma ou várias formações discursivas interligadas, que determinam o que pode e deve ser dito (articulado sob a forma de arenga, de um sermão, de um panfleto, de uma exposição, de um programa, etc.) a partir de uma posição dada em uma conjuntura dada) (HAROCHE; HENRY; PECHEUX, 1971, p.102).

Dessa definição, Adam (2008), ao compor ATD, faz um recorte, destacando os lugares sociais de interação que levam aos diferentes gêneros discurso:

Mesmo que a palavra não apareça, ao falar de discurso público, sermão, panfleto, exposição, programa, Pêcheux enumera uma lista de gêneros. O estabelecimento de uma ligação entre os gêneros e as formações sociodiscursivas é um dos avanços recentes da análise de discurso (ADAM, 2011, p. 44-45).

Ainda nesse recorte teórico, Adam (2011) deixa claro que não usa o termo "interdiscurso" de acordo com a abordagem lacanianaalthusseriana. Para a ATD, o sujeito é pragmático, dotado de intencionalidade, portanto, não é assujeitado. Essa concepção de sujeito tem reflexos em outros aspectos referentes ao discurso. O interdiscurso, nessa abordagem, é compreendido como um reservatório de memória onde se situam os modelos de gêneros e as relações com os discursos anteriores, o que "torna possível (prescrevendo ou proscrevendo) a formulação (ou formulações) dos enunciados" (ADAM, 2011, p. 45).

As diferenças entre o sujeito afetado pelo inconsciente,

linha francesa, remetemos a "Redefinições de conceitos da análise do discurso para a configuração da análise textual dos discursos" (JURACH, 2015). 
considerado pela análise do discurso de linha pecheutiana, e o sujeito intencional e pragmático, apontam para distinções epistemológicas importantes. A análise do discurso pecheutiana apresenta uma ruptura com as abordagens que consideram o sujeito uno e consciente. Segundo Possenti (2007, p. 364):

Aruptura com a pragmática tem comouma de suas consequências a ruptura com a psicologia, especialmente em sua modalidade cognitiva, tanto porque implica um certo conhecimento (da língua, do mundo, das regras), quanto, e, principalmente, porque essa psicologia desconhece o inconsciente.

Com esse entendimento, destacamos que a noção de sujeito intencional defendida por Adam (2008) é coerente com o pressuposto cognitivo de suas definições teóricas, ao destacar a atuação dos indivíduos por meio da linguagem. No interior da Semântica Cognitiva, a perspectiva talmyana destaca a constituição conceitual da linguagem pela percepção e pelas experiências dos indivíduos que utilizam a linguagem, dentro de uma cultura, incluindo aspectos afetivos e ideacionais, dentre eles, a intenção e a vontade.

Com isso posto, remetemos a um terceiro aspecto da relação teórica entre texto, discurso e cognição. Consideramos para este trabalho o caráter prototípico das sequências explicativas, de acordo com as esquematizações de Adam (2011). Para o autor, essa prototipicidade refere-se ao fato de que as sequências são construtos cognitivos que orientam os falantes na sua relação tanto de produção quanto de compreensão dos textos:

Dominar esse tipo de representações esquemáticas
prototípicas parece ter consequências sobre o armazenamento
de informações e o processamento da compreensão e do
levantamento de informações por meio de estratégias de
antecipação. A dificuldade de compreensão de textos orais
ou escritos por crianças e indivíduos não especialistas parece
ser explicada, pelo menos em parte, pela falta de controle dos
padrões textuais prototípicos. (ADAM, 2001, p.7, tradução
nossa).

Nesse sentido, precisamos considerar que nem sempre todas as macroproposições, conforme identificadas por Adam (2001) na esquematização dos protótipos explicativos, estão explícitas e completas na materialidade textual, podendo também haver períodos explicativos curtos, inseridos em gêneros discursivos que têm outras sequências como 
v. 7 (1)

215-231

jan/jun

2017

dominantes. Sobre as sequências explicativas e a constituição de gêneros discursivos, Wachowicz (2015, p. 138-139) oferece esclarecimentos em uma perspectiva cognitiva:

O raciocínio cognitivo de base da explicação é a causa, que pressupõe uma ligação explicativa entre dois ou mais fenômenos. Por esse motivo, a sequência explicativa é muito mais constituidora de outras sequências e/ou gêneros do que uma forma autônoma de construir gêneros, como acontece com a narrativa e com a argumentação.

Dessa forma, por essa característica de cognitivamente estruturar-se por causas e efeitos de fenômenos, as sequências explicativas comumente aparecem como constitutivas, por exemplo, de gêneros discursivos com caráter argumentativo. Como queremos fazer uma aproximação entre os esquemas sequenciais definidos por Adam (2001; 2008), optamos por utilizar, sobretudo, textos com a sequência explicativa como dominante, gêneros discursivos explicativos de divulgação científica, os quais atendem ao conjunto de macroproposições de base dos esquemas explicativos prototípicos.

\section{Os sistemas cognitivos de estruturação conceitual}

Nos dois volumes de Toward a cognitive semantics, Talmy (2001) define quatro sistemas cognitivos principais para o estudo da estruturação conceitual da linguagem: o sistema de configuração do espaço e do tempo; o sistema de distribuição de atenção; o sistema de perspectiva; e o de encaixamento. Para o estudo dos protótipos sequenciais explicativos, optamos por nos focar nos dois primeiros, apesar de os demais² também serem atuantes.

O sistema de configuração do tempo e do espaço é responsável por três eixos de percepção expressos na estruturação da linguagem: discreto/ contínuo, limitado/ilimitado, único/plural. Conforme esses eixos, nossa percepção organiza temporalmente, no eixo contínuo, atividades e, no eixo discreto, atos e eventos. Espacialmente, sobre o eixo contínuo percebemos massa e, sobre o eixo discreto, objetos. Além disso, essas porções podem ser percebidas como um conteúdo único ou como plurais. A figura a seguir apresenta as operações entre esses eixos:

\footnotetext{
${ }^{2}$ Sistema de perspectiva diz respeito ao olhar mental que se tem sobre uma cena ou seus participantes, ou seja, configura-se como um ponto de vista que enquadra uma atividade ou evento. Já o sistema de encaixamento permite estruturar sentenças em que os elementos se relacionam por subordinação, o que remete à recursividade da língua.
} 
Figura 1: Eixos de percepção do tempo e do espaço (adaptada de Talmy, 2001, p. 59).

Discreto

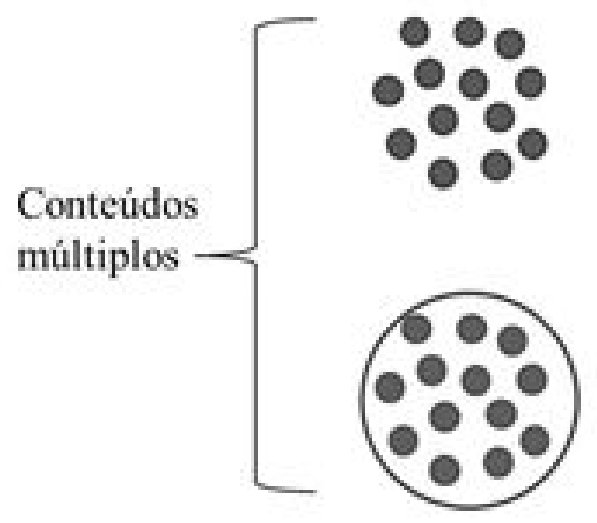

Continuo
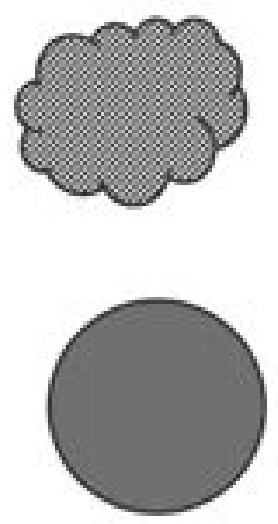

llimitado (interrelação de conceitos estáticos e dinâmicos no espaço)

\section{Limitado} (composição de objeto ou massa)

\section{Conteúdo único}

Essas percepções sobre conteúdos são representadas na linguagem e compõe as inter-relações que permitem expressar, por exemplo, como um volume se relaciona com outro no espaço, como um objeto é constituído por partes menores (parte e todo), como uma sequência de eventos e/ou atividades levam a um efeito (causa e consequência). Ao considerar que as sequências textuais, na maneira como são esquematizadas por Adam (2008), apresentam uma relativa estabilidade nas macroproposições que as constituem, destacamos que a evidenciação da atuação desses processos cognitivos auxilia na compreensão da estrutura conceitual mobilizada nas sequências. Com o foco nos protótipos explicativos, verificamos ser relevante, neste trabalho, investigar a atuação de outro sistema cognitivo, o sistema de distribuição de atenção, conforme Talmy (2001).

A percepção de atividades e eventos, envolvendo objetos ou massa, acontece por diferentes forças que direcionam a atenção de alguém sobre os referentes e a cena. Com isso, a distribuição da atenção reflete-se na linguagem pela organização das relações entre participantes de uma atividade ou evento, em funções sintáticas de sujeito ou de objeto, remetendo às relações entre causa e resultado. Essa atenção volta-se para a expressão de uma cadeia causal, em que processos dinâmicos levam a transformações ou consequências, o que também pressupõe uma sucessão temporal.

Segundo Talmy (2001), essa cadeia causal resulta de um 
v. 7 (1)

215-231 jan/jun 2017

enquadramento perceptual ("windowing of attention") sobre os elementos que compõem um evento de movimento ou mesmo estático. Dessa forma, a percepção dos eventos envolve um ponto de vista e, assim, um posicionamento. As sequências explicativas voltamse retoricamente para o estabelecimento de consensos e, para isso, costumam constituir-se pelo detalhamento de processos, a fim de validar pontos de vista. Logo, o sistema de distribuição de atenção será uma das bases das considerações sobre a estruturação linguística das sequências explicativas, sem desconsiderar os aspectos textuais e discursivos que as constituem.

\section{As macroproposições explicativas e os processos cognitivos}

Como partimos da noção de sequências explicativas pelo viés textual e discursivo, envolvemos, no processo de discussão dos processos cognitivos que atuam nessas sequências, fatores cotextuais e contextuais. Começaremos detalhando o esquema sequencial de base apresentado por Adam (2011).

A relação entre o POR QUE, pronome interrogativo, e o PORQUE, conjunção explicativa, é a base da estrutura linguística das sequências explicativas. Esses operadores permitem os desdobramentos entre as macroproposições explicativas, que correspondem, segundo Adam (2011), ao seguinte modelo:

Figura 2: Esquema de base das sequências explicativas (Adam, 2011)

\section{Sequência explicativa}

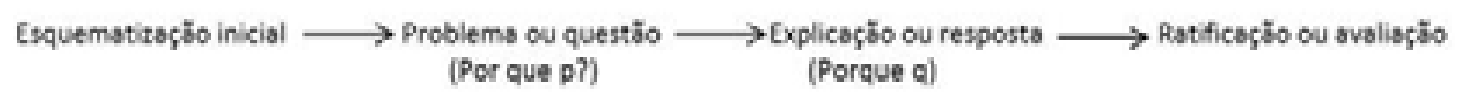

Adam (2011, p. 245) cita os modelos de Grize (1990) e Gaulmyn (1986) para compor essa definição das fases constitutivas das sequências explicativas. Conforme a estrutura acima, a esquematização inicial é, geralmente, subentendida e diz respeito à introdução do elemento problematizado, o que acontece frequentemente por segmentos descritivos. Se esse elemento é apresentado em um cotexto anterior ao questionamento, o pronome interrogativo POR QUE (?) atua como retomada e problematização. Quando subentendido, na maioria das vezes 
a esquematização do problema aparece na estrutura aberta pelo pronome interrogativo: POR QUE p (?). A fase do problema ou questionamento evidencia os papéis do sujeito que explica e do sujeito a quem se destina a explicação. Em seguida, a fase da resposta, representada canonicamente pela conjunção explicativa "PORQUE", possui os desenvolvimentos da explicação, a qual pode envolver processos causais. Depois da resposta, a macroproposição de ratificação ou avaliação é uma forma de reiterar a explicação a partir de um suposto consenso.

O modelo apresentado por Adam (2011) é uma forma de evidenciar as fases de questionamento, resolução e conclusão envolvidas nas sequências explicativas complexas. Contudo, a explicação pode aparecer também em períodos curtos. Ao tratar da estrutura da explicação, Adam (2011) faz uma relação entre os períodos explicativos e os princípios indutivos da lógica aristotélica, a partir do tradicional modelo de inferência: [SE p, então q), utilizado geralmente em contextos argumentativos. Sobre essa relação com a lógica, precisamos ser cautelosos. Conforme o autor, a explicação é uma forma de inversão da indução, pois remete a uma estrutura [SE q É PORQUE p]. Esse tipo de relação é questionável, pois, em um quadro lógico, a afirmação do consequente não assegura a verdade do antecedente. Dessa forma, o procedimento explorado pelo autor pode funcionar de modo intuitivo, mas não lógico e, como simulação de valor lógico, também pode colaborar com o argumento de autoridade.

Segundo o autor, em períodos explicativos curtos com a estrutura SE p (introdutor de uma proposição que coloca um problema) seguida de É QUE q ou É PORQUE q (introdutores de uma explicação), essa pode ser transformada na estrutura [É (PORQUE/POR) q QUE p]. Esse modelo não segue procedimentos lógicos, no entanto, promove um efeito causal e compreende uma estrutura temporal.

As sentenças que envolvem uma sucessão temporal, mesmo que expressas não linearmente, constituem-se como relatos de eventos e, então, remetem a estruturas linguísticas que relacionam eventos e subeventos a partir da causalidade e, sobretudo, da presença de um causador, seja agente volitivo e intencional ou não. Essa estrutura de relato de eventos é guiada pelo sistema cognitivo de distribuição de atenção, que permite o estabelecimento de associações entre os eventos e a noção de sucessão e continuidade que sustenta a relação de causa, ou seja, de processo. Com base em Talmy (2001, p. 271, tradução nossa): 
v. 7 (1)

215-231

jan/jun

2017
O que em outras abordagens e em outros sistemas cognitivos pode ser entendido como um 'continuum causal' é, ao invés disso, na organização conceitual que parece estar por trás da linguagem e, sem dúvida, de sistemas cognitivos adicionais, prototipicamente conceituado como uma sequência de links de 'eventos' ou 'subeventos' - que é o equivalente a conceber uma continuidade em pacotes discretos - no sentido de que a causalidade aqui pode estar associada somente com o limite entre cada subevento e seu sucessor.

As macroproposições explicativas com verbos dinâmicos, segundo Comrie (1976), aqueles em que as fases de um evento são diferentes, de modo geral estão voltadas para o processo de transformação do objeto inicial e tendem a ser constituídas por uma sequência de eventos. $\mathrm{Na}$ descrição inicial, o objeto problematizado costuma ser apresentado como um "fato estabelecido" e, muitas vezes, estático. O processo de transformação explicado remete a um deslocamento temporal e, portanto, a uma sucessão de eventos.

Para exemplificar essa estrutura explicativa, podemos partir de períodos curtos, como o trecho de uma entrevista publicada na revista Veja (TEIXEIRA, 2009, on-line):

Por que Chávez continua sendo popular na Venezuela? Porque o alto preço do petróleo deu a ele uma enorme quantidade de dinheiro.

Essa relação entre as sentenças pode ser transformada nas estruturas abaixo, sendo que a primeira segue uma relação lógica e a segunda evidencia a sucessão temporal.

a. SE Chávez continua sendo popular na Venezuela, É PORQUE o alto preço do petróleo deu a ele uma enorme quantidade de dinheiro.

b. É PORQUE o alto preço do petróleo deu a ele uma enorme quantidade de dinheiro QUE Chávez continua sendo popular na Venezuela.

Na sentença b, que se organiza conforme a sucessão temporal, a locução formada pelo verbo de ligação no presente do indicativo, "continua", e pelo do verbo "ser", estático, no gerúndio - apresenta um fato estabelecido e ainda em curso, com aspecto durativo, cuja causalidade envolve um verbo dinâmico, "dar", no pretérito perfeito 
do indicativo, marcador de um processo encerrado que envolve temporalidade e sucessão.

No entanto, embora Adam (2011) não tenha destacado esse fato, a sucessão temporal não é um elemento fundamental para a constituição de um período explicativo, o que nos leva à seguinte especificação: nem toda explicação pressupõe a presença de um agente volitivo e intencional e de um processo que tem uma duração temporal. A explicação pode acontecer a partir de apresentação de propriedades e, nesse sentido, relaciona-se com períodos descritivos que explicam a motivação do estado, sem implicar mudança deste. Assim, a resposta explicativa pode acontecer a partir de um sistema cognitivo de configuração do espaço, pela relação de parte/todo, em que elementos constituintes do elemento problematizado são apresentados e permitem explicar o fenômeno questionado, o que compreende uma sequência descritiva.

Isso pode ser exemplificado com a relação estabelecida entre a problematização e a resposta, no texto a seguir:

Por que a maior parte dos vegetais é verde?

Porque as suas células estão recheadas de cloroplastos, umas bolsinhas verdes. "É dentro dos cloroplastos que fica a clorofila, substância também esverdeada que absorve a luz do sol e a transforma em energia", explica o botânico Fernando Roberto Martins, da Universidade Estadual de Campinas, interior de São Paulo (Superinteressante, 1999, on-line).

No exemplo acima, a explicação não envolve uma mudança de estado e acontece pela descrição de elementos constituintes do fenômeno questionado, no caso, pela evidenciação de propriedades constitutivas dos vegetais, que é feita com base em um conhecimento especializado, representado pela voz de autoridade do botânico citado. Adam (2011) não faz distinção entre as explicações em que não há uma relação causal provocada por algum agente, volitivo e intencional ou não, e aquelas que envolvem outros processos causadores, como a presença de determinadas propriedades. Mas se refere aos segmentos explicativosjustificativos e demonstra que "a explicação pode não ser conforme a verdade do mundo que conhecemos e permanecer estruturalmente uma explicação" (ADAM, 2011, p. 240). Essa estrutura explicativa, nesses casos, envolve um contrato de credibilidade-verdade.

Nesse sentido, cabe tratar das questões pragmáticas envolvidas 
v. 7 (1)

215-231

na explicação para que se estabeleça um consenso entre interlocutores. Isso porque a aceitação da explicação não está diretamente relacionada a valores de verdade demonstrados logicamente, mas ao nível de engajamento entre quem pratica a ação de explicar e o valor atribuído à explicação por quem a recebe. De acordo com Adam (2011, p. 241):

Como o objetivo último do compartilhamento de crenças é um objetivo de ação, a explicação aparece como um ato intermediário entre o objetivo ilocucionário primário da asserção (partilhar uma crença ou um conhecimento) e o objetivo último do ato (convencer para fazer agir).

Por isso, nos períodos explicativos de base, como [É (PORQUE/ POR) q QUE p], as proposições que dizem respeito a "p", fato estabelecido, e " $q$ ", causa, não se relacionam necessariamente por uma relação lógica e uma adequação a um estado do mundo, mas por uma visão do mundo de acordo com a crença proposta pelo responsável pela explicação, o qual se posiciona como uma testemunha que percebe as causas dos fatos problematizados. Essa visão de mundo nos faz remeter ao sistema de perspectiva e à noção de ponto de vista, conforme a abordagem cognitiva, que estão relacionados à constituição psicológica dos indivíduos, a qual compreende valores, crenças, visão de mundo e opiniões, assim como afetividade.

Na sequência textual em questão, o ponto de vista é exposto de modo a aparentar um distanciamento do locutor, que explica da posição de testemunha e não de agente da explicação. A sequência explicativa complexa, portanto, pode envolver estrategicamente uma suposta objetividade. Por esse motivo é recorrente, nas explicações de cunho científico, o uso da terceira pessoa. Entretanto, isso não é um critério necessário para que se possa falar em sequência explicativa, pois essa não está restrita ao domínio científico e, mesmo nesse, é possível que seja usada a primeira pessoa, sobretudo pelo caráter argumentativo. Inclusive, a inserção de sequências ou períodos explicativos, no interior de textos com dominância argumentativa, é frequente, pois o aparente distanciamento estabelecido pela relação de causalidade é uma estratégia para reforçar o ponto de vista.

A respeito das diferenças entre a sequência argumentativa e a explicativa, remetemos a Bonini (2005), no capítulo a respeito das sequências textuais na perspectiva pragmático-textual de Adam, em Gêneros: teorias, métodos, debates. 
(...) em relação à explicação, seu propósito é construir um desenho claro da idéia. Para isso, responde-se à questão Por quê? ou Como?, mostrando quadros parciais da significação da idéia. A sequência explicativa também se diferencia da argumentativa, pois não visa a modificar uma crença (visão de mundo), mas transformar uma convicção (estado de conhecimento). (BONINI, 2005, p. 223-224).

Bonini (2005) tem como base as noções teóricas de Adam, sobre as sequências, anteriores às publicações de A linguística textual: introdução à análise textual do discurso (2008). Mesmo assim, citamos o trecho acima para evidenciar a relação entre as sequências argumentativa e explicativa. Bonini (2005) atribui à sequência explicativa o objetivo de "transformar" um "estado de conhecimento", o que é diferente do movimento visado pela sequência argumentativa: "modificar uma visão de mundo". Por um lado, interpretamos que essa distinção feita pelo autor é condizente com a definição de Adam (2011) de que a explicação é "um ato intermediário" entre a partilha de crenças e o convencimento. Por outro lado, a colocação feita por Bonini (2005) pode ser questionada ao considerar que Adam (2011, p. 235), ao tratar das sequências argumentativas, enuncia que "A estratégia argumentativa visa a uma transformação dos conhecimentos", o que poderia levar a dizer que ambas, explicação e argumentação, têm a mesma finalidade. Por isso, preferimos adotar outra saída e afirmar que o objetivo da sequência explicativa é estabelecer um "consenso" a partir de conhecimentos que passam a ser compartilhados.

A diferenciação entre a explicação e a argumentação parece ficar mais clara por outro ponto, o do procedimento explicativo, comumente realizado pela apresentação de constituintes. Quando Bonini utiliza a expressão "mostrando quadros parciais" do elemento problematizado, refere-se a suas considerações sobre os processos cognitivos envolvidos nas sequências explicativas: "Compreensão de conceitos gerais (análise) e compreensão de conceitos particulares (síntese)" (BONINI, 2005, p. 212). Desse modo, as operações explicativas teriam como foco ou a decomposição em elementos constituintes (análise) ou a composição a partir desses elementos (síntese).

$\mathrm{Na}$ nossa abordagem com base em Talmy (2001), remetemos ao sistema cognitivo de configuração do espaço, para esses casos, mas acreditamos que a relação de causalidade, ou seja, o sistema de atenção, também atua fundamentalmente na constituição da sequência explicativa, assim como o sistema de perspectiva, responsável pelo 
v. 7 (1)

215-231

jan/jun

2017

ponto de vista, neste caso, pelo domínio de conhecimento ativado para a explicação dos constituintes, conhecimento este que passa a ser compartilhado.

Para verificarmos o funcionamento das macroproposições constitutivas de uma sequência explicativa, tomaremos como exemplo o texto abaixo:

Por que o céu é azul?

(S1) Quando a luz passa através de um prisma, seu espectro é dividido em sete cores monocromáticas, eis que surge um arco-íris de cores. (S2) A atmosfera faz o mesmo papel do prisma, atuando onde os raios solares colidem com as moléculas de ar, água e poeira e são responsáveis pela dispersão do comprimento de onda azul da luz.

(S3) Quando percebemos a cor de um objeto, é porque ele refletiu ou dispersou, de forma difusa, o comprimento de onda associado à luz de uma determinada cor. Por exemplo, uma folha verde utiliza todas as cores do espectro para fazer a fotossíntese, exceto o verde, que é refletido. (SÓ FÍSICA, 2015, on-line)

A esquematização inicial, nesse texto, é constituída por um período tipicamente descritivo, composto pela atribuição de um predicado a um sujeito, com verbo estático e no presente do indicativo, representante de um fato estabelecido: "(...) o céu é azul". Desse modo, é introduzido o objeto problematizado, na fase de questionamento, com a utilização do pronome interrogativo "Por que". O texto como um todo trata do objeto problematizado em três segmentos explicativos sucessivos (S1, S2 e S3). O primeiro, S1, oferece uma explicação geral sobre a percepção das cores e funciona como apoio para a compreensão do segundo. S2 é direcionado ao objeto problematizado e S3 retoma os anteriores e faz um papel de conclusão e ilustração.

A macroproposição seguinte ao questionamento, que inicia a resposta, em S1, é introduzida pela conjunção subordinada temporal "quando", o que já sugere que a explicação envolverá uma transformação, isto é, a causalidade será apresentada com a utilização de verbos dinâmicos. Esse encaminhamento se confirma ao analisar o enunciado como um todo. A ancoragem temporal, do primeiro enunciado, é constituída por um verbo dinâmico, "passa", cuja trajetória é marcada pela locução prepositiva "através de", formada pelo advérbio de modo e 
pela preposição. Essa relação remete à representação espacial envolvida no processo. O efeito desse processo aponta para um novo evento: "seu espectro é dividido em sete cores monocromáticas". Apesar da sucessão temporal do processo, o uso recorrente do presente do indicativo, nas sequências explicativas do domínio científico, volta-se para uma tentativa de consenso, pois traz um efeito temporal de "verdades sempre válidas para a explicação do fenômeno".

A conclusão do processo tem como introdutor o apresentativo "eis". Esse conector remete ao cotexto anterior, a fim de validar a relação causal, e enfatiza a consequência, de modo a fazê-la parecer evidente, a partir de uma observação compartilhada entre quem explica e seu interlocutor.

A essa sequência explicativa, completa em S1, segue-se outra, em S2, que se apoia, por analogia, à primeira. Novamente, há a utilização de verbos dinâmicos, no presente do indicativo, que funcionam no detalhamento dos constituintes que causam o fato problematizado.

No início do S3, a conjunção temporal remete à situação geral envolvida na explicação do objeto problematizado, "quando percebemos a cor de um objeto". Esse segmento explicativo possui verbos dinâmicos, mas, diferentemente dos anteriores, no pretérito perfeito do indicativo, porque enfatiza o resultado do processo detalhado nas sequências anteriores. Nesse sentido, tem um papel conclusivo. A apresentação de um exemplo, ao final de S3, é uma forma de reforçar a tentativa de consenso e o compartilhamento das "verdades" oferecidas pela explicação.

Com base nessas análises, podemos enumerar alguns traços recorrentes presentes da estruturação linguística e nos movimentos textuais das sequências explicativas. Quanto aos fatores morfossintáticos, assinalamos como elementos potencialmente recorrentes:

- Arelação explícita ou implícita entreo pronomeinterrogativo "por que" e a conjunção explicativa "porque";

- A relação entre verbos estáticos e dinâmicos, também marcadores de temporalidade;

- A presença de conectores, como "por consequência", "por isso", que estruturam linguisticamente a atuação dos sistemas de configuração de tempo e espaço, causalidade e perspectiva.

- O uso de expressões apresentativas como "eis que" e "é isso", que tendem a atuar sobre o estabelecimento de um 
v. 7 (1)

215-231 jan/jun 2017

consenso e dar ênfase à consequência.

- A presença de conectores de adição, como "além disso", "também" e "ainda", para a inclusão de mais de um núcleo explicativo;

- Aapresentaçãodeexemploseusodemarcadores deilustração, como "por exemplo", "assim", "entre outros", os quais tendem a remeter a fatos referentes a um conhecimento partilhado também por quem recebe a explicação.

Já sobre os fatores textual-discursivos, que envolvem os textos efetivos, identificamos como pontos de base:

- O desenvolvimento das macroproposições explicativas (esquematização inicial, questão, resposta, avaliação);

- O estabelecimento de consensos.

\section{Considerações finais}

O pressuposto cognitivo presente nas definições de Adam sobre as sequências textuais nos estimula a buscar que traços cognitivos sustentam os esquemas sequenciais prototípicos, conforme apresentados pelo autor. E é justamente porque tratamos de textos que a associação com a Semântica Cognitiva talmyana se mostra pertinente, visto que este autor envolve, em seus estudos sobre a estruturação da linguagem, aspectos perceptivos que não excluem a intenção e a cultura em que se inserem os indivíduos.

Por essa associação teórica, pudemos evidenciar traços linguísticos e movimentos textuais que tendem a ser recorrentes em sequências explicativas. O conhecimento dos movimentos cognitivos e das marcas linguísticas recorrentes nos esquemas explicativos potencialmente facilita práticas de análise linguística, porque esses elementos podem funcionar como ferramentas auxiliares em processos de análise de textos.

\section{Referências}

ADAM, J-M. Les textes: types et prototypes. 4. ed. Paris: Nathan, 2001.

La linguistique textuelle: introduction à l'analyse textuelle des discours. Paris: 2008. 
A linguística textual: introdução à análise textual dos discursos. Tradução de Maria das Graças Soares Rodrigues, João Gomes da Silva Neto, Luis Passeggi, Eulália Vera Lúcia Fraga Leurquin. 2. ed. São Paulo: Cortez, 2011.

BATORÉO, H. J. Enquadramento cognitivo para a estrutura narrativa: uma proposta de olhar para a narrativa a partir da perspectiva da Linguística Cognitiva de Leonard Talmy. Veredas, n. 1 e 2, v. 10, 2006. Disponível em:<http://www.ufjf.br/revistaveredas/files/2009/12/artigo025.pdf $>$.Acesso em 27 mar. 2015.

BONINI, A. A noção de sequência textual na análise pragmático-textual de Jean-Michel Adam. In: MEURER, J. L.; BONINI, A.; MOTTA-ROTH, D. (Orgs.). Gêneros: teorias, métodos, debates. São Paulo: Parábola Editorial, 2005.

COMRIE, B. Aspect: an introduction to the study of verbal aspect and related problems. Cambridge, Cambridge University Press, 1976.

GAULMYN, M-M. de. Apprendre à expliquer. TRANEL. Neuchâtel, Université de Neuchâtel, n. 11, 1986.

GRIZE, J-B. Logique et langage. Paris: Ophrys, 1990.

HAROCHE, C.; HENRY, P.; PECCHEUX, M.; (1971), "La sémantique et la coupure saussurienne: langue, langage, discours", Langages, 24, 93-106 (repris dans MALDIDIER, D. (éd. 1990), L'inquietud du discours. Textes de Michel Pêcheux, choisis et presents par D. Maldidier, Paris, Éditions des Cendres.

JURACH, J. M. Redefinições de conceitos da análise do discurso para a configuração da análise textual dos discursos. Trama, n. 22, v.11, 2015.

POSSENTI, S. Teoria do discurso: um caso de múltiplas rupturas. In: MUSSALIN, F.; BENTES, A. C. (Orgs.) Introdução à linguística: fundamentos epistemológicos. v. 3, 3. ed. São Paulo: Cortez, 2007.

QUANTO mais verde melhor. Superinteressante. São Paulo: Abril, 1999. Disponível em: <https://super.abril.com.br/comportamento/quanto-maisverde-melhor/>. Acesso em 15 ago. 2017.

SÓ FÍSICA. Por que o céu é azul? Porto Alegre: Virtuos. Disponível em: <http://www. sofisica.com.br/conteudos/curiosidades/ceu_azul.php>. Acesso em 28 abr. 2015

TALMY, L. Toward a Cognitive Semantics. vol. 1. The MIT Press, Cambridge, Massachussets, 2001.

TEIXEIRA, Duda. Veja Entrevista Guillermo Zuloaga: Na Venezuela, só sobrou ele. Veja. 02/08/2009. Rio de Janeiro: Abril, 2009. Disponível em: <https:// arquivoetc.blogspot.com.br/2009/08/veja-entrevista-guillermo-zuloaga. html >. Acesso em 15 ago. 2017.

WACHOWICZ, T. C. Avaliação de textos na escola. Curitiba, Intersaberes, 2015.

Recebido em: 15 de fev. de 2017.

Aceito em: 13 de jul. de 2017. 